\title{
A non-empirical model for gas transfer through circular nanopores in unconventional gas reservoirs
}

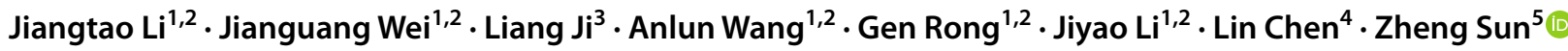

Received: 31 July 2018 / Accepted: 9 March 2021 / Published online: 26 March 2021

(c) The Author(s) 2021

\begin{abstract}
It is difficult to predict the flow performance in the nanopore networks since traditional assumptions of Navier-Stokes equation break down. At present, lots of attempts have been employed to address the proposition. In this work, the advantages and disadvantages of previous analytical models are seriously analyzed. The first type is modifying a mature equation which is proposed for a specified flow regime and adapted to wider application scope. Thus, the first-type models inevitably require empirical coefficients. The second type is weight superposition based on two different flow mechanisms, which is considered as the reasonable establishment method for universal non-empirical gas-transport model. Subsequently, in terms of slip flow and Knudsen diffusion, the novel gas-transport model is established in this work. Notably, the weight factors of slip flow and Knudsen diffusion are determined through Wu's model and Knudsen's model respectively, with the capacity to capture key transport mechanism through nanopores. Capturing gas flow physics at nanoscale allows the proposed model free of any empirical coefficients, which is also the main distinction between our work and previous research. Reliability of proposed model is verified by published molecular simulation results as well. Furthermore, a novel permeability model for coal/shale matrix is developed based on the non-empirical gas-transport model. Results show that (a) nanoconfined gastransport capacity will be strengthened with the decline of pressure and the decrease in the pressure is supportive for the increasing amplitude; (b) the greater pore size the nanopores is, the stronger the transport capacity the nanotube is; (c) after field application with an actual well in Fuling shale gas field, China, it is demonstrated that numerical simulation coupled with the proposed permeability model can achieve better historical match with the actual production performance. The investigation will contribute to the understanding of nanoconfined gas flow behavior and lay the theoretical foundation for next-generation numerical simulation of unconventional gas reservoirs.
\end{abstract}

Keywords Bulk-gas-transport model $\cdot$ Nanopores $\cdot$ Non-empirical $\cdot$ Production prediction

Jianguang Wei

weijianguang@163.com

$\triangle$ Zheng Sun

szcup613@163.com

1 Institute of Unconventional Oil and Gas, Northeast Petroleum University, Daqing 163318, China

2 Key Laboratory of Continental Shale Hydrocarbon Accumulation and Efficient Development, Ministry of Education, Northeast Petroleum University, Daqing 163318, China

3 PetroChina Coalbed Methane Company Limited, Beijing 100028, China

4 Shanxi Luliang Xiaoneng Mobile Energy Co. Ltd, Lüliang 032399, Shanxi, China

5 State Key Laboratory of Coal Resources and Safe Mining, China University of Mining and Technology, Xuzhou 221116, China

\section{Introduction}

In the past 10 years, the rapid development of unconventional gas reservoir has significantly shaped diverse aspects of global energy industry, including supply and demand pattern, recovery methods and technical innovation (Chu and Majumdar 2012; Ma et al. 2020; Dejam 2018; Sun et al. 2020). The unconventional gas reservoirs mainly incorporate shale gas reservoir, coal-bed methane and tight gas, the cumulative unconventional gas production reached $8228 \times 10^{8} \mathrm{~m}^{3}$, accounting for $23 \%$ of the global total (Jia 2017). And the value continues growing in recent years according to the International Energy Agency located at Paris (IEA 2016). However, relevant development technology for unconventional gas reservoir is still weak and need to be further studied urgently, especially for the understanding 
of diffusion and percolation in the matrix nanopores. Induced by the complexity of gas-transport mechanism through nanopores, it is difficult to make clear the production regularity of unconventional gas reservoir, leading to the large discrepancy between the predicted production and actual production (Kolesar et al. 1990; Gray 1987; Thimons and Kissell 1973; Deng et al. 2014; Ma et al. 2021). Hence, it highlights the need for establishing an accurate gas-transport model for the profitable development of unconventional gas reservoirs.

Rarefied gas flow takes place at both low-pressure and nanoscale geometry (Thompson and Owens 1975; Beskok et al. 1996; Harley et al. 1995). Utilizing atomic force microscopy (AFM), the nanopores and nanogrooves are detected for the first time in shale mudrocks (Javadpour 2009). And Fu observed that the pore size in coal matrix is less than $100 \mathrm{~nm}$ (Fu 2003). In addition, existed literature showed the presence of tremendous nanopores in shale and CBM reservoir (Howard 1991; Katsube 1992; Nelson 2009; Sun et al. 2019; Sakhaee-Pour and Bryant 2012). Moreover, initial formation pressure for the most CBM reservoir falls in the range of 4-8 MPa, and that for shale gas reservoir ranges from 15 to $44 \mathrm{MPa}$. During the depressurization development of unconventional gas reservoirs, pressure of the nearwell region will be considerably reduced due to the existence of pressure drop funnel. Hence, there must coexist multiple gas-transport mechanisms. And the gas-transport mechanism in the coal/shale matrix cannot be simply described by Knudsen diffusion. However, popular-utilized numerical simulation and recently proposed production prediction models for shale gas reservoirs employ Knudsen diffusion to represent the gas-transport capacity in the shale matrix (Cipolla et al. 2013; Wu et al. 2021; Zhao et al. 2020; Huang et al. 2021; Dejam 2019; Gale et al. 2007), which inevitably result in obvious deviation comparing the actual production behavior. As a result, it is crucial for the production prediction model or next-generation numerical simulator to account for the multiple gas-transport mechanism.

It is challenging to predict the flow performance in the nanoscale porous media since the standard assumptions of Navier-Stokes equation break down (Roy et al. 2003; Colin 2005). And the coexistence of multiple transport mechanism further aggravates the complexity of the issue, which encompass continuum flow, slip flow, transition flow and Knudsen diffusion. In general, the gas-transport regime can be categorized based on Knudsen number, which is defined as the ratio of the mean free path to characteristic length (Javadpour et al. 2007; Pandey et al. 2008; Taheri et al. 2009; Beskok and Karniadakis 1999; Wu et al. 2015). When the Knudsen number is lower than 0.001, the flow mechanism is the continuum flow which can be represented by Darcy's law (Wu et al. 2016a, b; Wu and Chen 2016; Ghanbarnezhad Moghanloo and Javadpour 2014). When
Knudsen number is in the range of $0.001-0.1$, it belongs to slip flow. Concentrating on the slip flow, lots of scholars have dedicated great efforts to the developments in the modeling of non-equilibrium boundary conditions (Maxwell 1878; Dejam et al. 2017; Ebert and Sparrow 1965; Spiga 1998; Sreekanth 1969; Piekos and Breuer 1996; Deissler 1964; Mitsuya 1993; Maurer et al. 2003; Colin and Caen 2004; Karniadakis and Bekok 2002; Sheng et al. 2019). Various slip boundary conditions are used to extend the application scope of standard Navier-Stokes equations to slip and transition flow regime, including first-order, second-order, and hybrid boundary conditions. When the Knudsen number is in the range of $0.1-10$, the flow mechanism belongs to the transition flow, and the flow characteristics of this regime are considered as the most difficult issue. When the Knudsen number is higher than 10 , the flow mechanism is free molecular diffusion which can be described by Knudsen diffusion (Mason et al. 1967; Yi et al. 2009; Guo et al. 2015; Bird 1998). Considering coexistence of multiple transport mechanism in the coal/shale matrix, a unified model covering entire range of Knudsen number will be favorable from practical purpose.

Currently, lots of approaches have been employed to address the problem, which can be classified as two types, i.e., molecular simulation and analytical model. When the rarefied effect becomes evident, an alternative method to continuum flow is the molecular simulation, which recognizes the fluid as a swarm of discrete particles (Bi and Nasrabadi 2019; Chen and Doolen 1998; Loyalka and Hamoodi 1990; Adzumi 1937a). In the molecular simulation, the position, inertia and the state of all individual particles are calculated either deterministically or probabilistically at all times. However, although recent advances have greatly improved computational performance, the molecular simulation is still computationally expensive and time-consuming, and it is unrealistic to simulate the gas production performance from unconventional gas reservoirs with the use of the present-day computers. In contrast, an analytical formula can not only provide instantaneous calculation results, but also conveniently identifies the effect of key physical properties. However, the majority of documented analytical models contain empirical coefficients, which greatly restrict its application (Javadpour 2009; Beskok and Karniadakis 1999; Wu et al. 2015, 2016a, b; Wu and Chen 2016; Karniadakis and Bekok 2002; Adzumi 1937b, c; Civan 2010; Civan et al. 2012, 2013; Azom and Javadpour 2012; Aguilera et al. 2012; Shahri et al. 2012; Klinkenberg 1941; Ettehad et al. 2012; Ertekin, et al. 2013; Karniadakis et al. 2005; Rahmanian et al. 2012; Shi et al. 2013; Singh et al. 2014). At the same time, for those analytical mathematic models without empirical coefficients, they cannot be applied to the entire range of Knudsen number (Liu et al. 2002; Knudsen 1909; Yang et al. 2013). 
In this work, the advantages and disadvantages of the existed analytical models are detailed reviewed. And it can be concluded that there exist two ways to develop a gastransport model. The first method is modifying a mature equation which is proposed for a specified flow regime and extend it to wider scope of application. Thus, gas-transport models based on the first method inevitably contains empirical coefficients. And the second method is weight superposition based on two different flow regimes, which is considered as the reasonable establishment method for universal non-empirical gas-transport model. Subsequently, according to slip flow and Knudsen diffusion, the unified non-empirical gas-transport model is established utilizing the second method. Most notably, the weight factors of slip flow and Knudsen diffusion are determined by Wu's model and Knudsen's model respectively, which capture the key transport mechanism in modeling bulk-gas transport through unconventional gas reservoir (Beskok and Karniadakis 1999; Wu et al. 2016b). Capturing gas flow physics at nanoscale allows the proposed model free of any empirical coefficients, which is also the main distinction between our work and previous research. Moreover, utilizing the non-empirical gastransport model, a novel permeability model for coal/shale matrix is established. The reliability of the permeability model is verified through the comparison with the published experimental data. Then, influences of pressure, nanoscale, real gas effect, contributions of slip flow and Knudsen diffusion are investigated. Finally, a realistic case study in Fuling shale gas field, China demonstrated that the numerical simulation coupled with the proposed permeability model can achieve better historical match. It further indicates the necessity for the production prediction model or numerical simulator to account for the varied gas-transport capacity within the shale matrix.

It should be noted that the proposed models are only dependent of Knudsen number and cover entire range of Knudsen number, it turns out to be simple and robust in the application. Moreover, the research expects to provide great convenience for field application and lay the foundation for the next-generation numerical simulator. The technical content of this research is arranged as follows. A brief introduction regarding gas-transport mechanisms in CBM and shale gas reservoirs is provided in "Gas transport mechanism through nanopores" section. Then, a comprehensive literature review about advantages and disadvantages of previous analytical gas-transport models is implemented in "Evaluation of the existed gas-transport model" section. After that, the unified non-empirical model based on the weight superposition of slip flow and Knudsen diffusion is proposed in "Establishment and validation of the proposed unified non empirical model" section, and the apparent bulk-gas permeability model is further developed in "Development of permeability model and analysis of influential factors" section.
Furthermore, a field case study with the intention to examine the feasibility of the proposed permeability model in "Field application" section. Finally, key conclusions are drawn.

\section{Gas-transport mechanism through nanopores}

\section{Matrix pore-scale and initial formation pressure of CBM and SG}

Compared with conventional oil/gas reservoirs, the existence of tremendous nanopores significantly increase the complexity of the recovery for coal-bed methane (CBM) and shale gas (SG) (Zou et al. 2011; Wu et al. 2014; Yan et al. 2013). Apparently different from the utilize of Darcy's law for the conventional reservoirs, the assumption of continuum flow breaks down when gas flows inside nanopores. Thus, the gas-transport mechanism through matrix nanopores in unconventional gas reservoir is still hard to be precisely characterized. Statistical data indicate that the pore radius for CBM is less than $100 \mathrm{~nm}$ and the reservoir depth generally ranges from 400 to $800 \mathrm{~m}$ (Fu 2003). Hence, initial formation pressure in coal seam can be assumed range from 4 to $8 \mathrm{MPa}$. In addition, Karacan and Siriwardane pointed out that the pore diameter in coal matrix is less than $10 \mathrm{~nm}$, similar to the size of several molecular (Siriwardane et al. 2009). Shale gas is self-generating and self-storage reservoir, which has low porosity (less than 10\%) and permeability (ranging from nano Darcy and micro Darcy) (Ghanizadeh et al. 2015). Howard demonstrated that the pore size in Frio shale falls between 5 and $15 \mathrm{~nm}$ (Howard 1991). Katsube found that the pore radius is between 2.7 and $11.5 \mathrm{~nm}$ with a depth of 4400-1500 m (Katsube 1992). By utilizing atomic force microscopy at the first time, Javadpour revealed the presence of nanopores in shale matrix (Azom and Javadpour 2012). And the formation pressure for $S G$ ranges from 15 to $44 \mathrm{MPa}$ (Wu and Chen 2016; Singh et al. 2014). In order to conveniently investigate the gas-transport mechanism, the radius of coal/shale matrix pores are assumed range from 1 to $50 \mathrm{~nm}$ in this work.

\section{The bulk-gas-transport mechanisms in CBM and SG}

The appropriate bulk-gas flow regimes are classified by Knudsen number $(\mathrm{Kn})$, which is defined as the ratio of a molecular mean free path (MFP) to characteristic length. The Knudsen number for the circular nanotube has the following form (Roy et al. 2003; Colin 2005; Javadpour et al. 2007; Pandey et al. 2008; Chen and Doolen 1998; Loyalka and Hamoodi 1990; Adzumi 1937a, 1937b, c; Civan 2010; Civan et al. 2013):

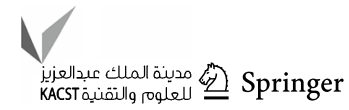


$\mathrm{Kn}=\frac{\lambda}{2 r}$

where $\lambda$ is the mean free path of gas molecules, $\mathrm{m} ; r$ is the radius of circular nanotube, $m$.

And the mean free path of gas molecules is defined as follows:

$\lambda=\frac{\kappa_{\mathrm{B}} T}{\sqrt{2} \pi \delta_{m}^{2} p}$

where $\kappa_{B}$ is Boltzmann constant with the value of $1.3805 \times 10^{-23} \mathrm{~J} / \mathrm{K} ; T$ is formation temperature, $\mathrm{K} ; p$ is the formation pressure, $\mathrm{Pa} ; \delta_{m}$ is the effective diameter of the gas molecules, $\mathrm{m}$.

Supposing the gas type is the pure methane, the mathematic relationship between MFP and pressure or temperature can be obtained according to formula (2).

From Fig. 1, it can be concluded that the mean free path of gas molecules is more sensible to formation pressure rather than the formation temperature. And the MFP will decrease with an increase in the pressure. Furthermore, the decrease rate turns to considerable fast when the pressure is less than $1 \mathrm{MPa}$ and will significantly mitigated when the pressure is higher than $1 \mathrm{MPa}$. Also, it can be found that the MFP will increase with an increase in temperature, while the amplitude is relatively small. Hence, the gas-transport mechanism in coal/shale matrix will significantly change with a decrease in the pressure. According to the above analysis, the key issue required to capture is the change rule between MFP and the formation pressure. According to the formation pressure and matrix pore-scale in CBM and SG, the gas-transport mechanism for the unconventional gas reservoirs can be revealed when the pressure is the initial reservoir pressure.

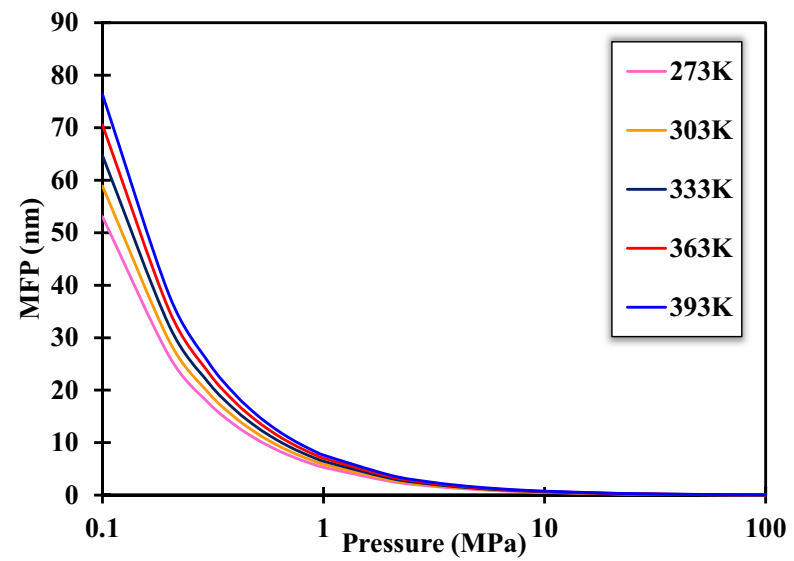

Fig. 1 The MFP under various pressure and temperature
As depicted in Fig. 2, the majority of the SG fall in the area of slip flow, and that for CBM fall in the region of transition flow. The reason behind this phenomenon is the difference of initial formation pressure between CBM and SG. According to Fig. 2, it can be also observed that the determination of gas-transport mechanism depends on the formation pressure and pore size. For the same pressure, Knudsen number of nanopores with small radius will greater than those with big radius. Knudsen number will greatly increase with the decline of pressure. Hence, it can be concluded that the main flow regimes of unconventional gas reservoir include slip flow, transition flow and Knudsen diffusion. However, the existed production prediction model or numerical simulator assume the gas-transport type in the shale matrix is Knudsen diffusion. It will result in great discrepancy regarding prediction performance. Remarkably, there exist difference of the gas-transport mechanism within the near-well and far-well region. It will be necessary to account for the varying gas-transport mechanism when predicting the production performance. Hence, the unified model with the able to incorporate slip flow, transition flow and Knudsen diffusion is highlighted to be addressed.

\section{Gas-transport mechanism in nanopores}

When Knudsen number is less than 0.001, fluid flux can be expressed by Hagen-Poiseuille equation:

$J_{c}=-\frac{\phi}{\tau} \frac{r^{2} p}{8 \mu R T} \frac{\mathrm{d} p}{\mathrm{~d} l}$

where $J_{c}$ represents the flow flux through nanopores, mol/ $\left(\mathrm{m}^{2} \cdot \mathrm{s}\right) ; \phi$ is the matrix porosity, decimal; $\tau$ is the tortuosity of the nanopores, dimensionless; $\mu$ is the gas viscosity, Pa.s;

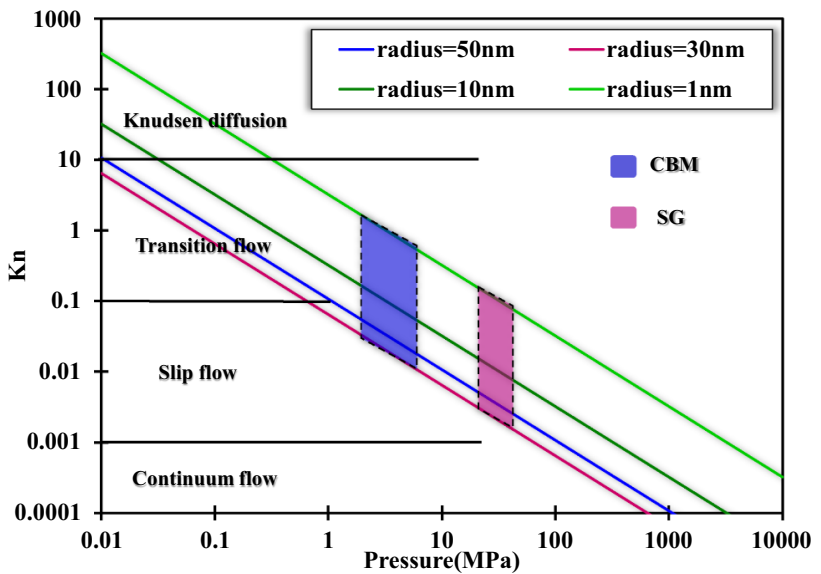

Fig. 2 The gas-transport mechanism through nanopores in CBM and SG 
$R$ is the universal gas constant with the value of $8.314, \mathrm{~J} /$ $(\mathrm{mol} \cdot \mathrm{K})$.

When $0.001<K n<0.1$, gas flow mechanism belongs to slip flow. After modification of slip boundary condition, the slip flow formula for nanopores is given below:

$J_{\mathrm{s}}=-\frac{\phi}{\tau} \frac{r^{2} p}{8 \mu R T}\left(1+\frac{4 \mathrm{Kn}}{1-b \mathrm{Kn}}\right) \frac{\mathrm{d} p}{\mathrm{~d} l}$.

However, the definition of Knudsen number in Eq. (4) is the ratio between MFP and pore radius, which is different from the definition in this research (See Eq. (2)). Hence, Eq. (4) should be transformed into the following expression:

$J_{\mathrm{s}}=-\frac{\phi}{\tau} \frac{r^{2} p}{8 \mu R T}\left(1+\frac{8 \mathrm{Kn}}{1-2 b \mathrm{Kn}}\right) \frac{\mathrm{d} p}{\mathrm{~d} l}$

where $J_{\mathrm{s}}$ is the slip flow flux through nanopores, $\mathrm{mol} /\left(\mathrm{m}^{2} \mathrm{~s}\right)$; $b$ is modification factor, dimensionless. When employing the first-order slip boundary condition, the value is equal to zero. If the second-order slip boundary is utilized, the value is -1 . Moreover, molecular simulation and experimental results have demonstrated that the second-order boundary condition is more reasonable. As a result, Eq. (5) can be further derived:

$J_{\mathrm{s}}=-\frac{\phi}{\tau} \frac{r^{2} p}{8 \mu R T}\left(1+\frac{8 K n}{1+2 K n}\right) \frac{\mathrm{d} p}{\mathrm{~d} l}$.

When the Knudsen number is greater than 10, the gas flow can be described by Knudsen diffusion, which has the following expression:

$J_{\mathrm{k}}=-\frac{\phi}{\tau} \frac{2 r}{3}\left(\frac{8}{\pi R T M}\right)^{0.5} \frac{\mathrm{d} p}{\mathrm{~d} l}$

where $J_{\mathrm{k}}$ is the Knudsen diffusion flux through nanopores, $\mathrm{mol} /\left(\mathrm{m}^{2} \cdot \mathrm{s}\right) ; M$ is gas molar mass, $\mathrm{Kg} / \mathrm{mol}$.

To investigate contribution of different gas-transport mechanisms, the ratio between slip flow flux and Knudsen diffusion flux and the ratio between slip flow flux and continuum flow flux are analyzed.

$\frac{J_{\mathrm{s}}}{J_{\mathrm{k}}}=\frac{3 \pi}{128 \mathrm{Kn}}\left(1+\frac{8 \mathrm{Kn}}{1+2 \mathrm{Kn}}\right)$

$\frac{J_{\mathrm{s}}}{J_{c}}=1+\frac{8 \mathrm{Kn}}{1+2 \mathrm{Kn}}$.

As depicted in Fig. 3, when the Knudsen number is lower than 0.001, transport capacity of Knudsen diffusion can be neglected compared with slip flow. When the Knudsen number is higher than 10 , the transport capacity of slip flow can be neglected compared with Knudsen diffusion. Thus, the transport capacity of slip flow is equal to the continuum flow

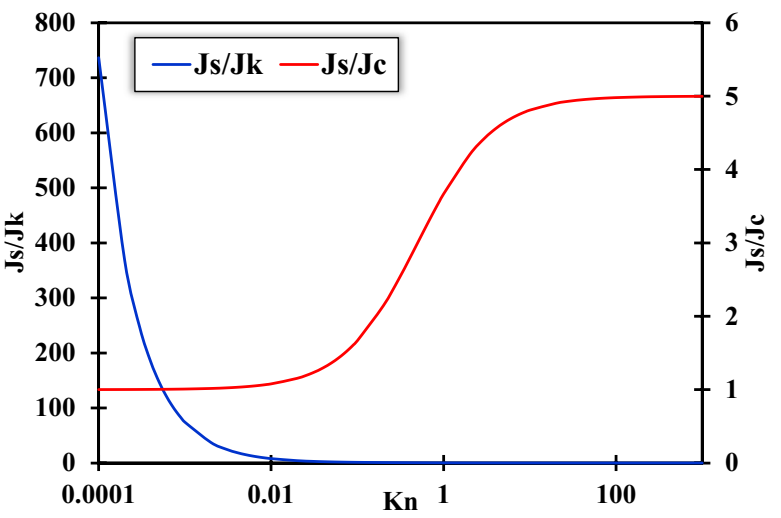

Fig. 3 The variation curve between the $J_{c} / J_{\mathrm{k}}$ and Knudsen number

when the Knudsen number is lower than 0.001 . When the Knudsen number is higher than 10 , the transport capacity of slip flow is nearly 5 times of the continuum flow. In the other words, the slip equation degenerates to continuum equation when the Knudsen number is lower than 0.001 .

\section{Evaluation of the existed gas-transport model}

It can be concluded that there exist two ways to develop a unified gas-transport model. The first method is modifying a mature equation which is initially for a specified flow regime and extend its application scope to a wider range. And the second method is weight superposition based on two different flow regimes.

By introducing a correction into slip flow equation, which was named as the rarefaction effects coefficient, a simple physics-based unified model is developed for entire flow regime. The reliability of this model was validated through the comparison with molecular simulation results and experimental data. And the concrete formula of Beskok model has the following form:

$J_{\text {Beskok }}=-\frac{\phi}{\tau} \frac{r^{2} p}{8 \mu R T}\left(1+\frac{8 \mathrm{Kn}}{1+2 \mathrm{Kn}}\right) C_{\mathrm{r}}(\mathrm{Kn}) \frac{\mathrm{d} p}{\mathrm{~d} l}$

where the $J_{\text {Beskok }}$ is the bulk-gas flow flux through nanopores in the Beskok model, $\mathrm{mol} /\left(\mathrm{m}^{2} \mathrm{~s}\right)$; the $C_{\mathrm{r}}(\mathrm{Kn})$ is the rarefaction coefficient.

Because the mature formula for a single flow regime fails to cover all range of Knudsen number, the models based on the first method inevitably need empirical coefficients. Without any doubt, it will constrain its application to a certain extent. And the second method is weight superposition based on two different flow regimes, which 
is considered as the reasonable establishment method for universal non-empirical gas-transport model.

The model developed by Knudsen is an interpolating function determined by a fit to experimental data, is the combination between molecular flow from kinetic theory and the Poiseuille flow equation for viscous flow. And the concrete expression is given below:

$J_{\text {Knudsen }}=J_{c}+\frac{\mathrm{Kn}+1.25}{\mathrm{Kn}+1.55} J_{\mathrm{k}}$

where the $J_{\text {Knudsen }}$ is the bulk-gas flux using the Knudsen model, $\mathrm{mol} /\left(\mathrm{m}^{2} \cdot \mathrm{s}\right)$.

Notably, the application scope of Knudsen model is the transition regime and Knudsen diffusion. In order to conveniently compare the calculation data from existed bulkgas model with published molecular simulation results (Adzumi 1937a), the equation proposed by Knudsen is treated dimensionless.

$\frac{J_{\text {Knudsen }}}{J_{c}}=1+\frac{128 \mathrm{Kn}}{3 \pi} \frac{\mathrm{Kn}+1.25}{\mathrm{Kn}+1.55}$

$\frac{J_{\text {Knudsen }}}{J_{\mathrm{k}}}=\frac{3 \pi}{128 \mathrm{Kn}}+\frac{\mathrm{Kn}+1.25}{\mathrm{Kn}+1.55}$.

In 1937, through a great deal of experimental research on the flow of gaseous mixtures through capillaries, Adzumi introduces a contribution coefficient term $(\varepsilon)$ to establish a unified bulk-gas-transport model through nanopores. Unfortunately, Adzumi did not propose any formula or analytical formula for $\varepsilon$. The model proposed by Adzumi has the following expression:

$J_{\text {Adzumi }}=J_{c}+\varepsilon J_{\mathrm{k}}$

where the $J_{\text {Adzumi }}$ is the bulk-gas flux using the Adzumi model, $\mathrm{mol} /\left(\mathrm{m}^{2} \mathrm{~s}\right)$, the $\varepsilon$ is the contribution coefficient proposed by Adzumi, dimensionless.

Consistent with the Adzumi model, Liu developed a bulk-gas-transport model by defining the expression for $\varepsilon$. He pointed out that the slip layer has different thickness for nanopores with different radius. Hence, the ratio of slip layer to whole cross-section can be regarded as $\varepsilon$ :

$\varepsilon=4 \mathrm{Kn}-4 \mathrm{Kn}^{2}$

From Eq. (15), it can be found that the contribution coefficient turns to zero when $\mathrm{Kn}$ is equal to one. Hence, when the $\mathrm{Kn}$ is greater than one, the model proposed by Liu is not a reasonable approach. Similarly, to conveniently compare the accuracy between the existed bulk-gas model and molecular simulation results, the equation proposed by Liu is dimensionless treated as follows:
$\frac{J_{\mathrm{Liu}}}{J_{c}}=1+\left(4 \mathrm{Kn}-4 \mathrm{Kn}^{2}\right) \frac{128 \mathrm{Kn}}{3 \pi}$

$\frac{J_{\mathrm{Liu}}}{J_{\mathrm{k}}}=\frac{3 \pi}{128 \mathrm{Kn}}+4 \mathrm{Kn}-4 \mathrm{Kn}^{2}$

where the $J_{\text {Liu }}$ is the bulk-gas flux using the Liu model for circular nanotube, $\mathrm{mol} /\left(\mathrm{m}^{2} \mathrm{~s}\right)$.

Citing the formula (14) proposed by Adzumi, Ertekin proposed a gas-transport model which is weight superposition of continuum flow and Fick's diffusion. However, the contribution of each flow regime remains unchanged with varying Knudsen number, resulting in that the model proposed by Ertekin cannot cover the whole flow regime.

Through linear superposition of Knudsen diffusion and slip flow, Javadpour proposed an analytical model for gas transfer through nanopores. But the model contains an empirical coefficient known as the tangential momentum accommodation coefficient (TMAC), which is defined as the fraction of gas molecules reflected diffusively from a wall compares with perfect mirror-like reflection. Similar with Javadpour, accounting for the effect of wall roughness on Knudsen diffusion, the gas-transport model proposed by Darabi contains the TMAC.

By linear superposition of continuum flow and Knudsen diffusion, Singh proposed a non-empirical model for bulkgas-transport model for nanopores. But the Singh model is only valid when the Knudsen number is less than one:

$J_{\text {Singh }}=J_{c}+J_{\mathrm{k}}$.

After dimensionless treatment, the following equation can be expressed as:

$\frac{J_{\text {Singh }}}{J_{c}}=1+\frac{128 \mathrm{Kn}}{3 \pi}$

$\frac{J_{\text {Singh }}}{J_{\mathrm{k}}}=\frac{3 \pi}{128 \mathrm{Kn}}+1$

By weight superposition of slip flow and Knudsen diffusion, Wu proposed unified models for bulk-gas transfer through nanopores. However, neglecting the different definition of Knudsen number between Beskok model and Wu model, the formula and numerical simulation data are wrongly derived (Beskok and Karniadakis 1999; Adzumi 1937a). Moreover, the developed model by Wu for nanopores contain the same rarefaction coefficient which is introduced by Beskok. And the weight factors in Wu model are determined by probabilities between gas molecules colliding with each other and colliding with nanopore surface.

In summary, the majority of documented analytical models contain empirical coefficients. Moreover, for those 
proposed models without empirical coefficients, they cannot cover entire range of Knudsen number. Hence, a novel unified bulk-gas-transport models for nanopores which is free of any empirical coefficient is significantly urgent. In order to clearly show the advantages and disadvantages of previous models, detailed evaluation are tabulated below:

\section{Establishment and validation of the proposed unified non-empirical model}

\section{The determination of the weight factors}

From Table 1, these models based on the second establishment method can be further divided into two categories. Several models are the weight superposition of continuum flow and Knudsen diffusion, and the other models are the combination based on slip flow and Knudsen diffusion. According to the conclusion of "Gas-transport mechanism in nanopores" section, the slip flow can degenerate into continuum flow when the Knudsen number is less than 0.001. The slip flow formula can characterize the gas flow in both range of continuum and slip regime. Moreover, because the range of Knudsen number for slip flow is more closely related to transition flow compared with continuum flow, the characteristics of slip flow will be more similar to the transition flow compared with continuum flow. From this perspective, the establishment method which is weight superposition of slip flow and Knudsen diffusion will be more sensible.

The weight factors in the $\mathrm{Wu}$ model are determined by probabilities between gas molecules colliding with each other and colliding with nanopore surface. Through the comparison with molecular simulation data and experimental results, it can be concluded that the Wu model is more accurate in the range of slip flow rather than the range of Knudsen diffusion. Hence, the weight factor for slip flow in $\mathrm{Wu}$ model can be employed to develop the novel non-empirical model in this paper. Considering the derivation error in the $\mathrm{Wu}$ model for nanopores, the expression of weight coefficient for slip flow in the proposed model can be derived:

$\omega_{\mathrm{s}}=\frac{1}{1+\beta \mathrm{Kn}}$.

Through the comparison with simulation data, the value of $\beta$ is determined as 9 . Thus, the ultimate expression of weighted coefficient for slip flow in the proposed model is:

$\omega_{\mathrm{s}}=\frac{1}{1+9 \mathrm{Kn}}$.

For the weight coefficient of Knudsen diffusion in the proposed models, it can be obtained through the Knudsen model, which can achieve an excellent match with the experimental data:

$\frac{J_{\text {Knudsen }}}{J_{\mathrm{k}}}=\frac{3 \pi}{128 \mathrm{Kn}}+\frac{\mathrm{Kn}+1.25}{\mathrm{Kn}+1.55}$.

When the Knudsen number lies in the range of Knudsen diffusion, the first term on the right side of equation can be neglected. Hence, weight coefficient of Knudsen diffusion can be determined as follows:

$\omega_{\mathrm{k}}=\frac{\mathrm{Kn}+1.25}{\mathrm{Kn}+1.55}$.

In this paper, the weight factors of slip flow and Knudsen diffusion are obtained by Wu model and Knudsen model respectively, which capture the key bulk-gas-transport mechanism. The relationship between weight coefficients and Knudsen number is plotted in Fig. 3.

As depicted in Fig. 4, the weight coefficient of Knudsen diffusion will increase with an increase in the Knudsen number and the weight coefficient of slip flow will decrease with an increase in the Knudsen number. When the Knudsen number is less than 0.001 , the weighted coefficients of slip flow and Knudsen diffusion are 1 and 0.8 respectively.

Table 1 Evaluation of existed bulk-gas-transport models in nanopores

\begin{tabular}{|c|c|c|c|}
\hline Models & Establishment method & Application scope & $\begin{array}{l}\text { Empirical } \\
\text { coeffi- } \\
\text { cients }\end{array}$ \\
\hline Knudsen & Second method (continuum flow and Knudsen diffusion) & $\mathrm{Kn}>1$ & None \\
\hline Liu & Second method (continuum flow and Knudsen diffusion) & $\mathrm{Kn}<1$ & None \\
\hline Beskok & First method (slip flow) & Cover all regimes & One \\
\hline Javadpour & Second method (slip flow and Knudsen diffusion) & Cover all regimes & One \\
\hline Ertekin & Similar to Liu model & Not for transition flow & None \\
\hline Darabi & Similar to Javadpour model & Cover all regimes & One \\
\hline Singh & Second method (continuum flow and Knudsen diffusion) & $\mathrm{Kn}<1$ & None \\
\hline Wu and Chen (2016) & Second method (slip flow and Knudsen diffusion) & Wrongly derived & One \\
\hline
\end{tabular}




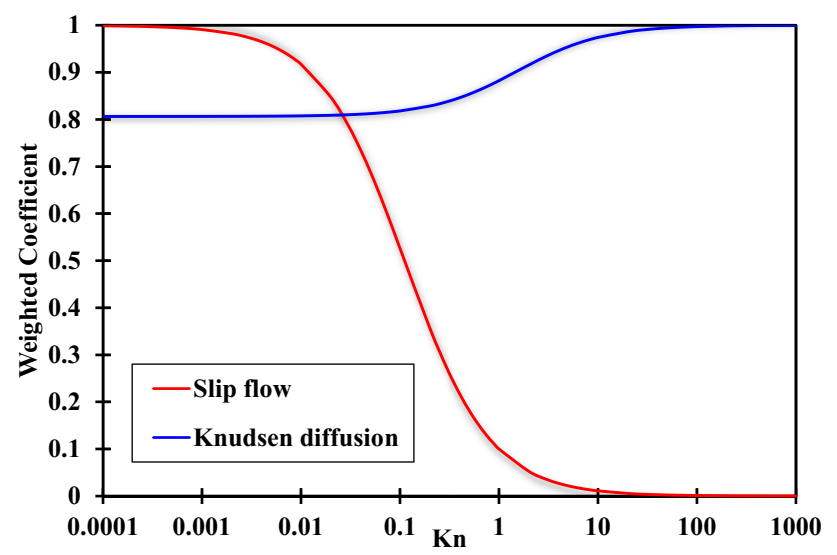

Fig. 4 The varying curve of weighted coefficients to Knudsen number

The Knudsen diffusion can be neglected when the Knudsen number is less than 0.001 , thus the proposed model can be degenerated to continuum flow. When the Knudsen number is higher than 10, the weight coefficients of Knudsen diffusion and slip flow become 1 and 0, respectively. Hence, the proposed model will degenerate to Knudsen diffusion. That is to say the proposed model will degenerate to continuum flow when the Knudsen number is less than 0.001 and degenerate to Knudsen diffusion when the Knudsen number is higher than 10 .

\section{The establishment and validation of the transport model for nanopores}

According to the text mentioned above, the weight coefficients for slip flow and Knudsen diffusion are given. Hence, the ultimate expression of unified gas-transport model can be described:

$J_{\text {Proposed }}=\omega_{\mathrm{s}} J_{\mathrm{s}}+\omega_{\mathrm{k}} J_{\mathrm{k}}$.

To verify the reliability of the proposed model, the published molecular simulation data (Adzumi 1937a) is employed to compare with the calculation data by proposed model. Furthermore, in order to highlight the characteristic of high accuracy with the proposed model, all existed nonempirical models other than Ertekin model, which is seriously unreasonable for the determination of weight factors, are included in the comparison. After dimensionless treatment, the proposed model for nanopores can be transformed as follows:

$\frac{J_{\text {Proposed }}}{J_{c}}=\left(1+\frac{8 \mathrm{Kn}}{1+2 \mathrm{Kn}}\right) \frac{1}{1+9 \mathrm{Kn}}+\frac{128 \mathrm{Kn}}{3 \pi}\left(\frac{\mathrm{Kn}+1.25}{\mathrm{Kn}+1.55}\right)$
$\frac{J_{\text {Proposed }}}{J_{\mathrm{k}}}=\frac{3 \pi}{128 \mathrm{Kn}}\left(1+\frac{8 \mathrm{Kn}}{1+2 \mathrm{Kn}}\right) \frac{1}{1+9 \mathrm{Kn}}+\frac{\mathrm{Kn}+1.25}{\mathrm{Kn}+1.55}$.

Due to the unreasonable weighted coefficient for Knudsen diffusion in Liu model, the model cannot be applied into the situation when Knudsen number is higher than 1 . As depicted in Figs. 5 and 6, the calculated results from Knudsen model and Singh model always overestimate the transport capacity compared with molecular simulation data. And the Knudsen model is more accurate compared with Singh model. In the entire range of Knudsen number, the reliability of proposed model is verified with excellent agreement compared with molecular simulation results. The high accuracy of the proposed model was demonstrated by comparing with the other existed non-empirical models. Hence, the proposed model for nanopores can be applied to all flow regimes with

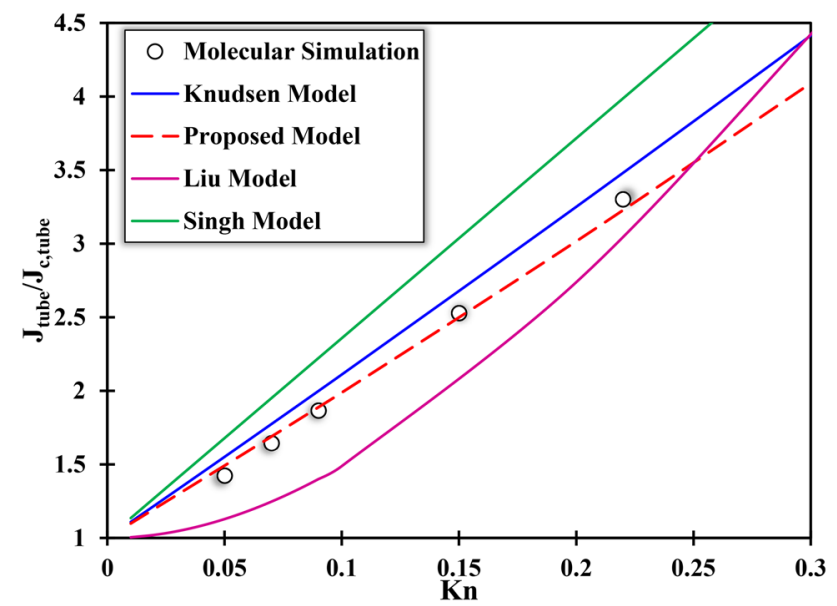

Fig. 5 Comparison of gas-transport models with molecular simulation results in the slip and early transitional flow regimes

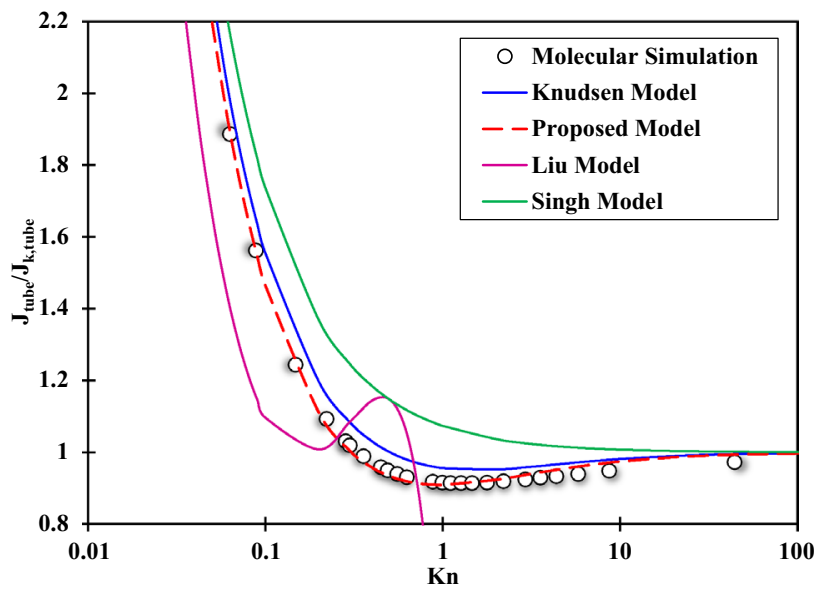

Fig. 6 Comparison of gas-transport models with molecular simulation results in the transition flow and Knudsen diffusion regimes 
high accuracy. It should be noted that the novel analytical model is free of any empirical coefficients, which turns out to be simple and robust in the practical application.

In summary, the proposed models for nanopores can provide the advantages of significantly simplicity and preciseness compared with existed models. The reasons behind the phenomenon are the reasonable weighted factors determined by Knudsen model and Wu model, which capture the key transport mechanism in modeling bulk-gas transport through unconventional gas reservoir. In addition, due to the feature of high accuracy of proposed models, it can be utilized to shed light on the relationships between each of variables and the gas-transport capacity in nanopores.

\section{Development of permeability model and analysis of influential factors}

\section{Establishment of permeability model for nanopores}

As the key property of coal/shale matrix, the permeability can characterize the gas-transport capacity of the nanopores. Because the existed production prediction models or numerical simulators consider that the flow mechanism in coal/ shale matrix belongs to Knudsen diffusion, which is against the actual gas-transport type in the development process of unconventional gas reservoirs. The majority of the SG are in the range of slip flow and the majority of the CBM are in the range of transition flow. Thus, it highlights the need to establish a permeability model for coal/shale matrix. According to Eq. (25), the apparent permeability for nanopores can be described:

$k_{\text {app }}=\frac{\phi}{\tau} \frac{r^{2}}{8+72 \mathrm{Kn}}\left(1+\frac{8 \mathrm{Kn}}{1+2 \mathrm{Kn}}\right)+\frac{\phi}{\tau} \frac{\mathrm{Kn}+1.25}{\mathrm{Kn}+1.55} \frac{2 r}{3}\left(\frac{8 R T}{\pi M}\right)^{0.5} \frac{\mu}{P}$

where the $k_{\text {app }}$ is the apparent permeability for gas transport through nanopores, $\mathrm{nD}$.

Through the nitrogen adsorption method and mercury injection method, Yang measured the average matrix pore radius of three shale samples in Sicuan basin, China (Zou et al. 2011). Subsequently, the pressure-decay method is utilized to obtain the permeability of the shale matrix. With the objective of verifying the reliability of the proposed permeability model, we perform the comparison between the calculation results of the proposed model and published permeability data. The basic pore structure parameters are collected in Table 2.

As shown in Fig. 7, the proposed model can match the experimental data. Meanwhile, the deviation of the permeability model is apparent, especially for the sample M03. The deviation of the model may be caused by the following three reasons. Firstly, the proposed model does not account
Table 2 Pore structure parameters of shale

\begin{tabular}{llll}
\hline Core samples & Average porosity & Tortuosity & $\begin{array}{l}\text { Average } \\
\text { pore radius } \\
(\mathrm{nm})\end{array}$ \\
\hline M01 & 0.099 & 5.46 & 7.56 \\
M02 & 0.072 & 6.50 & 7.78 \\
M03 & 0.082 & 7.35 & 7.97 \\
\hline
\end{tabular}

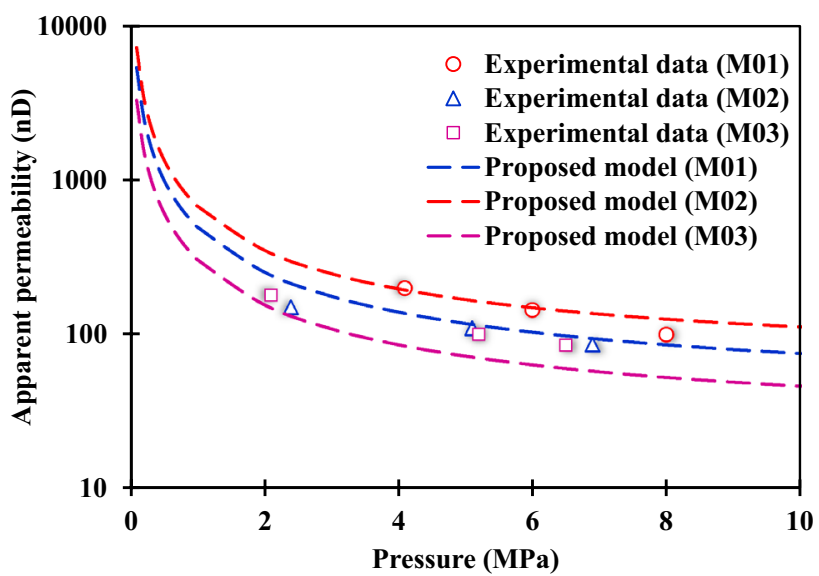

Fig. 7 The comparison between the proposed permeability model and experimental data

for the real gas effect. The gas physical property will change with the pressure and temperature. However, the idea gas is adopted in our model, neglecting the real gas effect. Secondly, the permeability model is established in terms of the circular nanotube. However, there may exist slit nanopores or naturally fractures in the coal/shale matrix. Finally, the average pore radius is utilized to calculate the permeability for the matrix, without considering the influence of the pore-size distribution. However, it should be noted that the accuracy of the proposed permeability model in this work can meet the requirement of the engineering application. Moreover, if the real gas effect or pore-size distribution is considered, much additional work needs to be implemented and the simplicity of the proposed permeability model will be greatly weakened. Utilizing the permeability model, we can investigate the influence of pore-scale on the gas-transport capacity and the contributions of slip flow and Knudsen diffusion.

\section{The pore scale}

The pore size plays a significantly crucial role in determining the apparent permeability which is the key factor for the profitable development of unconventional gas reservoirs. Hence, it is crucial to shed light on the effect of nanopore 
Table 3 Summary of modeling parameters utilized in the calculation

\begin{tabular}{llll}
\hline Parameter & Symbol & Unit & Value \\
\hline Porosity & $\phi$ & Dimensionless & 0.05 \\
Gas viscosity & $\mu$ & Pa s & $1.49 \times 10^{-5}$ \\
Tortuosity & $\tau$ & Dimensionless & 4.3 \\
Molar mass of gas & $M$ & $\mathrm{Kg} / \mathrm{mol}$ & $1.6 \times 10^{-2}$ \\
Universal gas constant & $R$ & $\mathrm{~J} /(\mathrm{mol} \mathrm{K})$ & 8.314 \\
Radius of nanotube & $r$ & $\mathrm{~nm}$ & $1-50$ \\
\hline
\end{tabular}

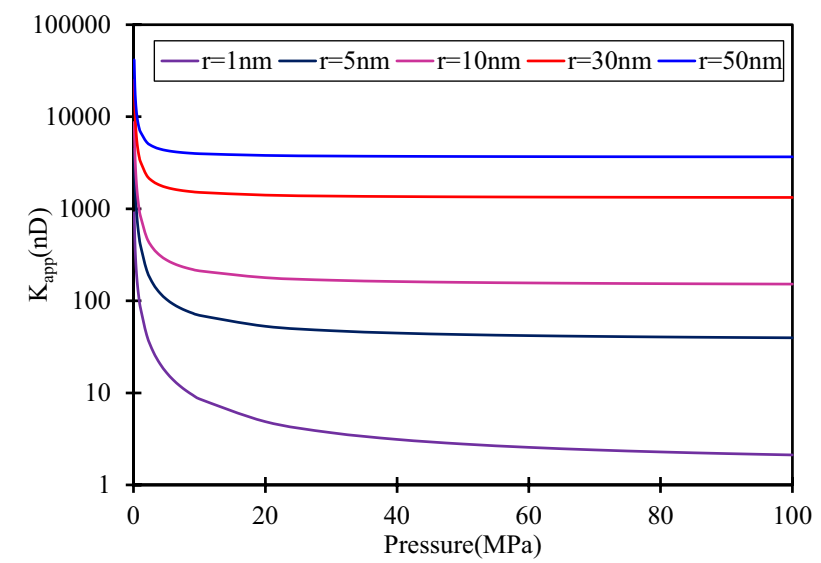

Fig. 8 The apparent permeability of circular nanotube with different radius

scale on the apparent permeability. In this case, the nanopores with five different radii are adopted. Assuming the formation temperature is $473 \mathrm{~K}$. And the other parameters required in the calculation process are tabulated in Table 3.

From Fig. 8, it can be concluded that the gas-transport capacity will increase with a decrease in the pressure. However, there exist great difference in the increase characteristics for nanopores with different radius. For the nanopores with $30 \mathrm{~nm}$ radius, when the pressure is higher than $10 \mathrm{MPa}$, the gas-transport capacity nearly remains unchanged. When the pressure is lower than $2 \mathrm{MPa}$, the gas-transport capacity will significantly increase with a decrease in the pressure. For the nanopores with $1 \mathrm{~nm}$, it can be found that the gastransport capacity will significantly increase when the pressure is less than $10 \mathrm{MPa}$. In order to describe this phenomenon better, a new parameter named enhancement pressure (EP) is introduced. When the pressure is lower than EP, the gas-transport capacity will be greatly enhanced. Remarkably, the value of EP will increase with a decrease in the pore size of nanopores. It can be also found that the gas-transport capacity for nanopores with large radius will always greater than the nanopores with small radius.

In order to investigate the gas-transport capacity contributed by slip flow and Knudsen diffusion, the corresponding equations are given below. Based on the parameters which

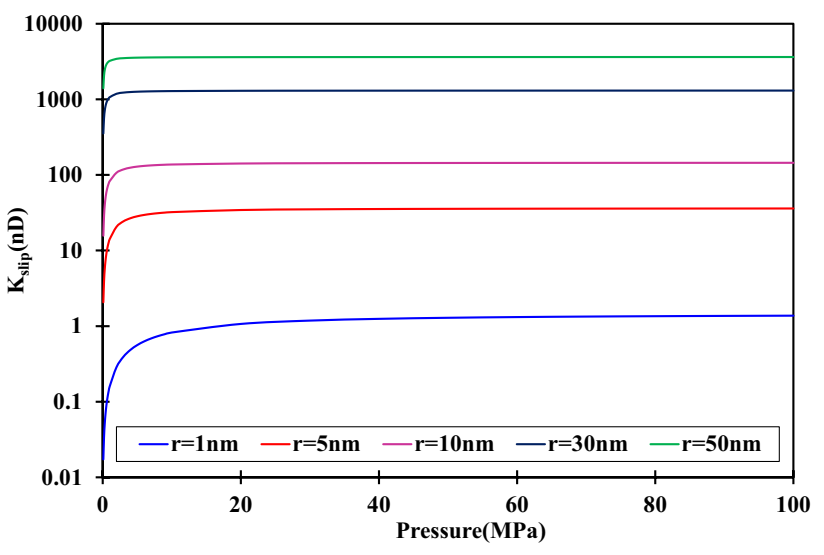

Fig. 9 The gas-transport capacity of slip flow with different radius

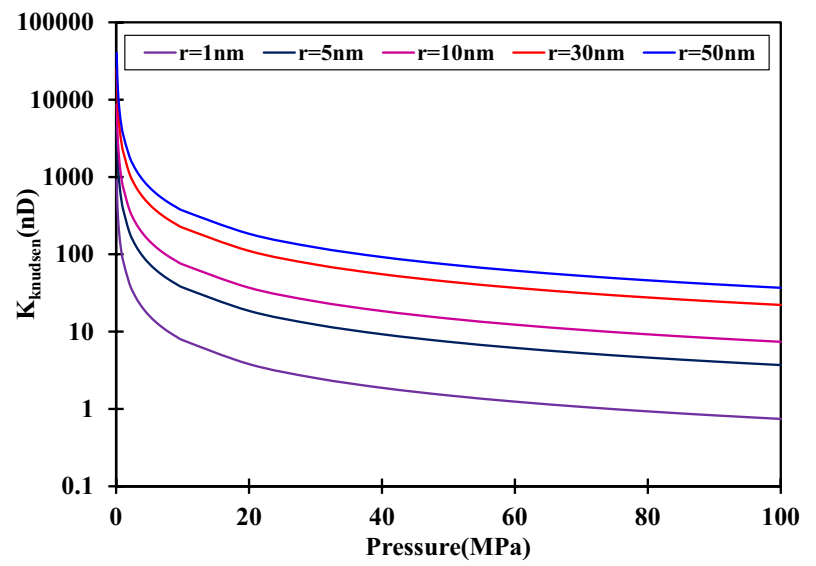

Fig. 10 The gas-transport capacity of Knudsen diffusion with different radius

are shown in Table 3, we can quantitatively shed light on the gas-transport capacity during the depressurization development of unconventional gas reservoir.

$k_{\text {slip }}=\frac{\phi}{\tau} \frac{r^{2}}{8+72 \mathrm{Kn}}\left(1+\frac{8 \mathrm{Kn}}{1+2 \mathrm{Kn}}\right)$

$k_{\mathrm{knudsen}}=\frac{\phi}{\tau} \frac{\mathrm{Kn}+1.25}{\mathrm{Kn}+1.55} \frac{2 r}{3}\left(\frac{8 R T}{\pi M}\right)^{0.5} \frac{\mu}{P}$.

From Fig. 9, it can be observed that the gas-transport capacity of slip flow will increase with an increase in pressure. As shown in Fig. 10, the gas-transport capacity of Knudsen diffusion will decrease with an increase in the pressure. Similarly, when the pressure is higher than EP, the gas-transport capacity of both slip flow and Knudsen diffusion are slightly changed. However, when the pressure is less than EP, the gas-transport capacity of Knudsen diffusion will be significantly improved and the gas-transport capacity 
of slip flow will drop rapidly. It can be also concluded that the varied amplitude of Knudsen diffusion is wider than slip flow. During the depressurization development process, the gas-transport capacity of nanopores with small radius is always less than the nanopores with large radius. In addition, for the production well in unconventional gas field, the flow regime for the vicinity of the well may be the Knudsen diffusion. However, the gas-transport mechanism of far-well zone may belong to the slip flow. It highlights the difference of gas-transport mechanism in different flow region of the unconventional gas reservoir. Hence, the production prediction model or next-generation numerical simulator should account for the proposition.

\section{The contributions of slip flow and Knudsen diffusion}

The proposed model is developed by weight superposition of slip flow and Knudsen diffusion. In order to investigate the contribution of each flow mechanism to the gas-transport capacity through the nanopores, according to formula (28) (29) (30), the contributions of slip flow and Knudsen diffusion for nanopores are defined as follows:
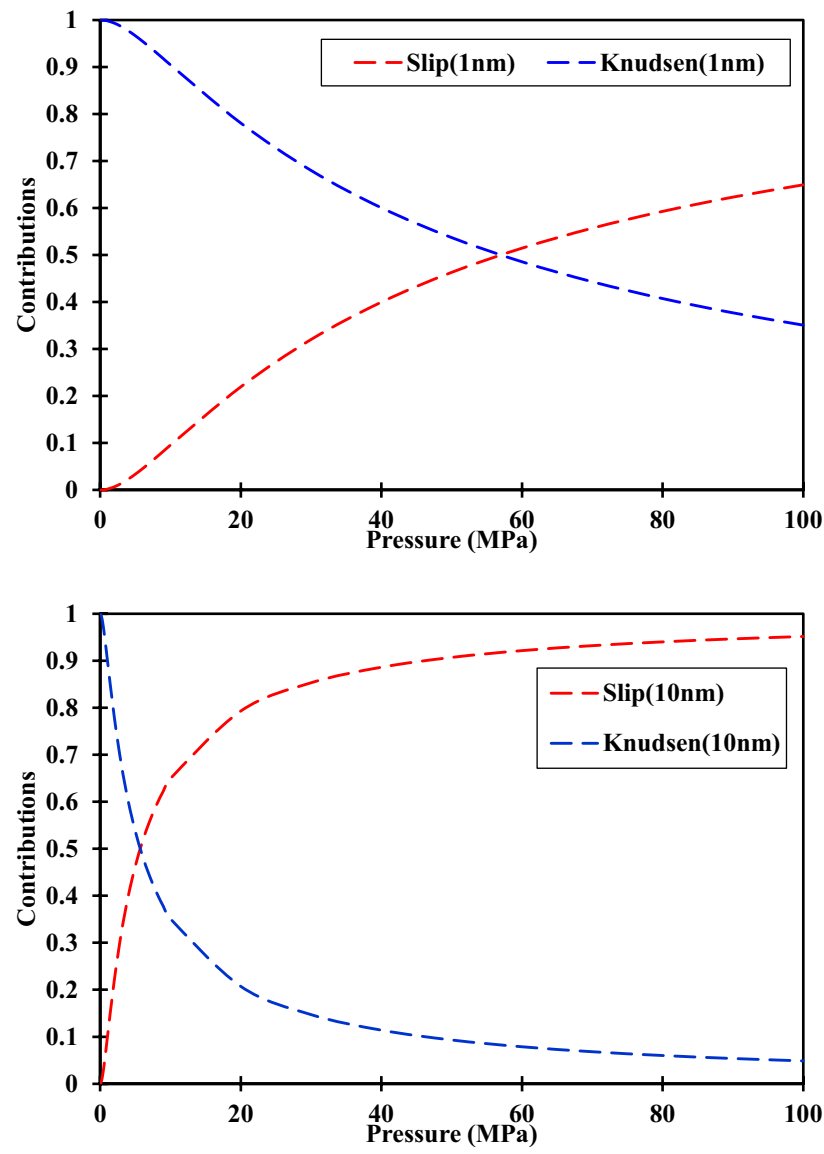

$C_{\text {slip }}=\frac{k_{\text {slip }}}{k_{\text {app }}}$

$C_{\text {knudsen }}=\frac{k_{\text {knudsen }}}{k_{\text {app }}}$

where the $C_{\text {slip }}$ is the contribution of slip flow for circular nanotube, decimal; $C_{\text {Knudsen }}$ represents the contribution of Knudsen diffusion for circular nanotube, decimal.

Figure 11 shows that the contribution of slip flow will increase with increasing formation pressure and the contribution of Knudsen diffusion will decrease with the increase in the formation pressure. For the nanopores with $1 \mathrm{~nm}$ radius, when the pressure is less than $58 \mathrm{MPa}$, the contribution of Knudsen diffusion is greater than slip flow. The contribution of different transport mechanisms is varied smoothly in this case. For the nanopores with $30 \mathrm{~nm}$ radius, the contribution of different transport mechanism changes dramatically when the pressure is lower than $5 \mathrm{MPa}$. And it can be also found that the slip flow will dominate the gastransport capacity when the pressure is higher than $60 \mathrm{MPa}$.
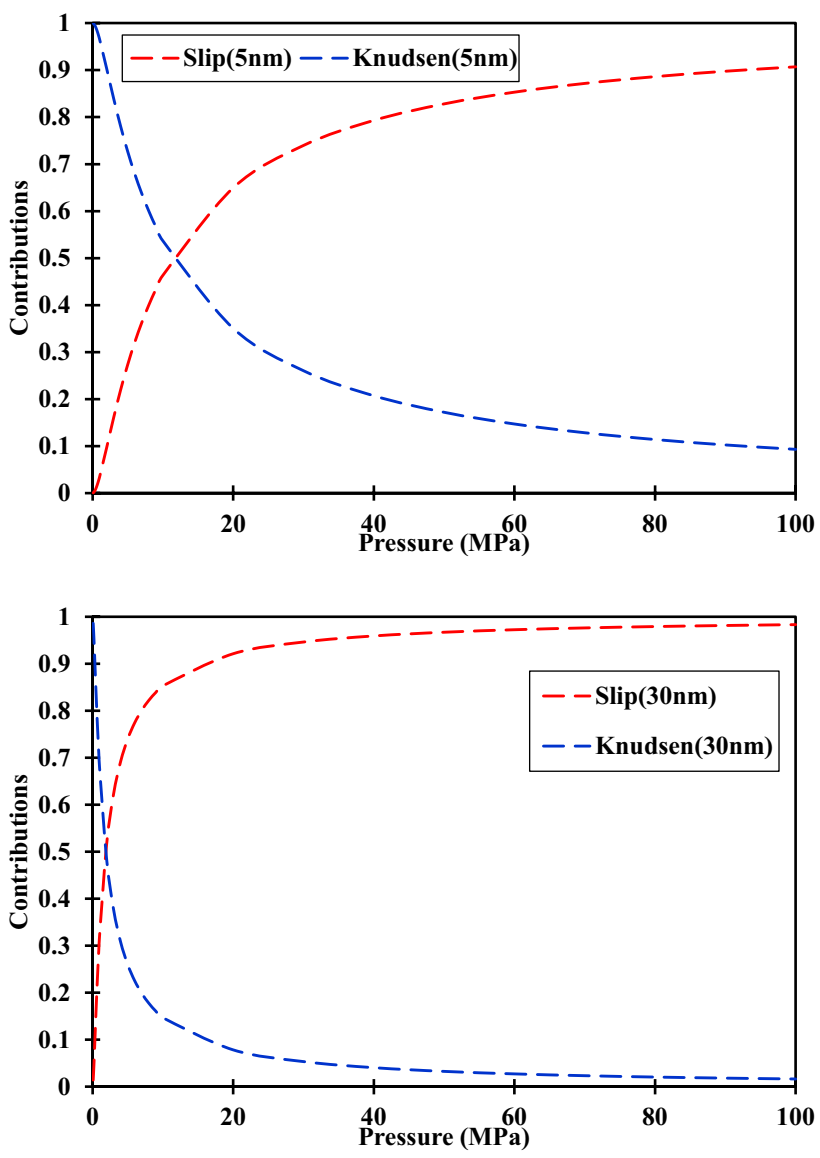

Fig. 11 The contributions of slip flow and Knudsen diffusion with pressure 
The reason behind the above phenomenon is that the value of Knudsen number. The Knudsen diffusion will dominate the gas-transport capacity when the gas encounters the lowpressure and small-radius nanopores. With an increase in the pressure, the Knudsen number will decrease rapidly (See Fig. 2). Thus, the Knudsen diffusion will dominate the gastransport capacity when the pressure is relatively low and the slip flow will dominate when the pressure is relatively high.

\section{Field application}

Lots of research has been devoted to investigating the production performance of shale gas well and a great deal of production prediction models have been established, which can be divided as dual porosity-single permeability, dual porosity-dual permeability, and dual porosity-three permeability. However, the existed production prediction models or numerical simulator for a shale gas well all consider the gas-transport type in shale matrix as Knudsen diffusion, which fails to characterize the actual transport capacity. As a result, the prediction data from previous models are smaller than the actual production behavior, which cannot provide reliable guidance for efficient development. Hence, it will be attractive for the existed numerical simulator to account for actual gas-transport mechanism. In this section, an actual well in Fuling shale gas field is adopted, which is the first large shale gas field in China. Meanwhile, a numerical model was built by CMG based on the dual porosity-dual permeability, which is widely used and regarded as reliable reservoir simulation software in shale gas field application. The key physical parameters, isothermal adsorption curve and production performance are given below. With the objective of considering the actual gas-transport mechanism (See "Appendix 1"), we will compare the actual production

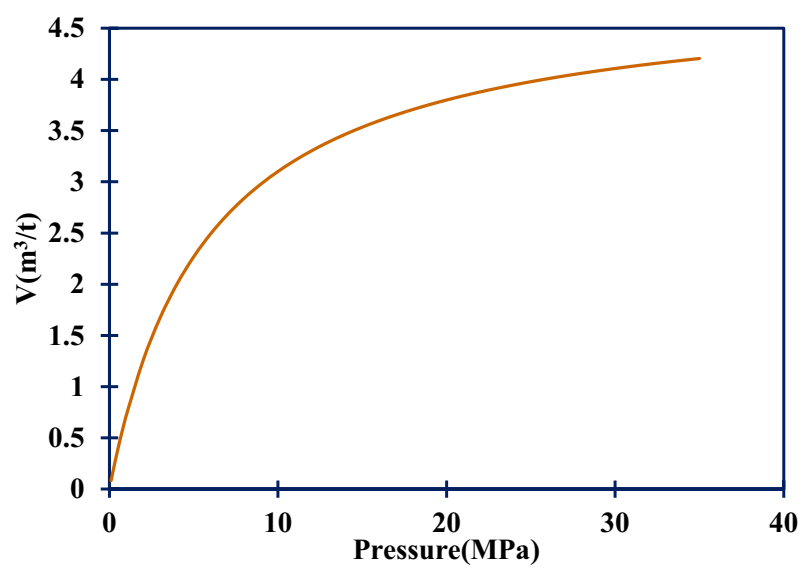

Fig. 12 The isothermal adsorption curve performance with results from CMG and CMG coupled revised permeability (Fig. 12).

Inputting these parameters collected in Table 4, the predicted production behavior from the numerical simulator can be obtained. It should be noted that the permeability of shale matrix is not provided. According to the average matrix radius, the value of matrix permeability can be calculated by Eq. 33 (See "Appendix 1"). Accounting for the actual gas-transport mechanism within the shale matrix, the revised permeability in this work can be calculated by Eq. 33 (See "Appendix 1"). Hence, the predicted production behavior from the numerical simulator coupled with revised permeability can also be determined. Finally, these results are compared with actual gas production to investigate the effect of the proposed permeability model on the production performance.

Table 4 Key physical parameters for the shale gas well

\begin{tabular}{ll}
\hline Parameters & Value \\
\hline Initial formation pressure (MPa) & 31.7 \\
Formation temperature (K) & 390 \\
Length of horizontal well (m) & 736 \\
Porosity of hydraulic fractures, fraction & 0.5 \\
Half-length of hydraulic fractures (m) & 53 \\
Porosity of the reservoir & 0.04 \\
Langmiur pressure (MPa) & 5.8 \\
Langmiur volume (m 3 /t) & 4.9 \\
Average matrix radius (nm) & 8.1 \\
Permeability of hydraulic fractures (mD) & 1500 \\
Numbers of hydraulic fractures & 12 \\
Bottom-hole pressure (MPa) & 3.1 \\
\hline
\end{tabular}

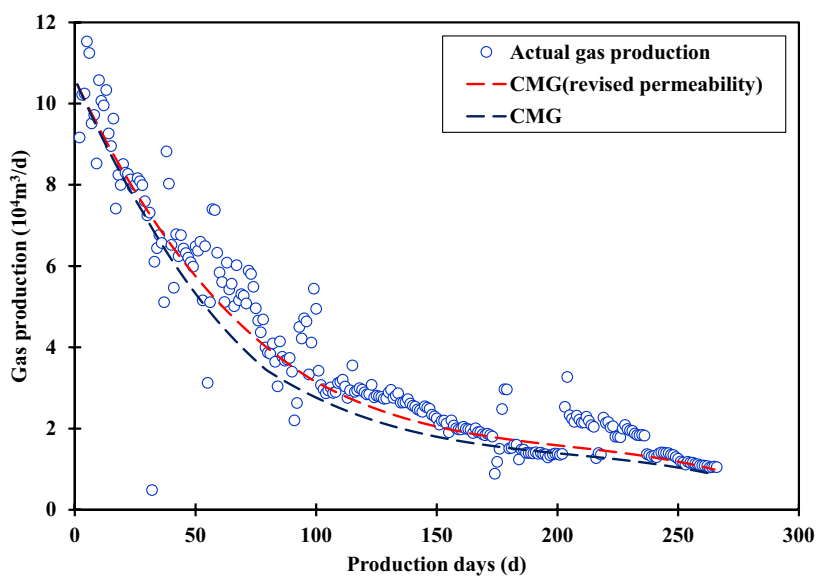

Fig. 13 The comparison of actual gas production and numerical simulation data 
As shown in Fig. 13, it can be found that the results from CMG coupled with revised permeability are higher than the production performance from CMG. And the production behavior from CMG coupled with revised permeability is closer to the actual gas production, which is considered as the better historical match compared with CMG. Through the comparison with actual cumulative gas production, it can be also demonstrated that the cumulative gas production from CMG coupled with revised permeability is more accurate than CMG. The reason behind this phenomenon is that we account for the actual gas-transport mechanism in the matrix. In the vicinity of the production well, the Knudsen diffusion dominates the gas-transport capacity. Hence, the matrix permeability calculated by Knudsen diffusion and proposed permeability model is approximately the same. However, for the far-well region of the production well, the gas-transport mechanism converts into transition flow or slip flow. Thus, the matrix permeability of the far-well region is underestimated by existed numerical simulator. Therefore, the production data from CMG coupled with revised permeability is higher compared with CMG. At the early production stage, because the gas production is mainly determined by the near-well zone which belongs to the Knudsen diffusion, the deviation between CMG and CMG coupled with revised permeability is relatively small. With the production process, the drainage area gradually expands outwards and the far-well region will gradually affect the production performance. Hence, the deviation between CMG and CMG coupled with revised permeability becomes larger. After the drainage area reaches the boundary, the region which is dominated by Knudsen diffusion becomes bigger during the depressurization development process. Hence, at the late production stage, the deviation between CMG and CMG coupled with revised permeability becomes small again.

In summary, the accuracy of the CMG coupled with revised permeability is reflected through the comparison with CMG and actual gas production. And it is concluded that the proposed permeability model can effectively improve the existed numerical simulator to better historical match the actual production performance. Furthermore, the reasons for the deviation between CMG and CMG coupled with revised permeability are detailed analyzed (Fig. 14).

\section{Summary and conclusions}

According to the aforementioned context, the majority of documented analytical gas-transport models contain empirical coefficients, which greatly restrict its application. At the same time, for those analytical mathematic models without empirical coefficients, they cannot be applied to the entire range of Knudsen number. In contrast, the proposed model is free of any empirical coefficients and capable of covering the

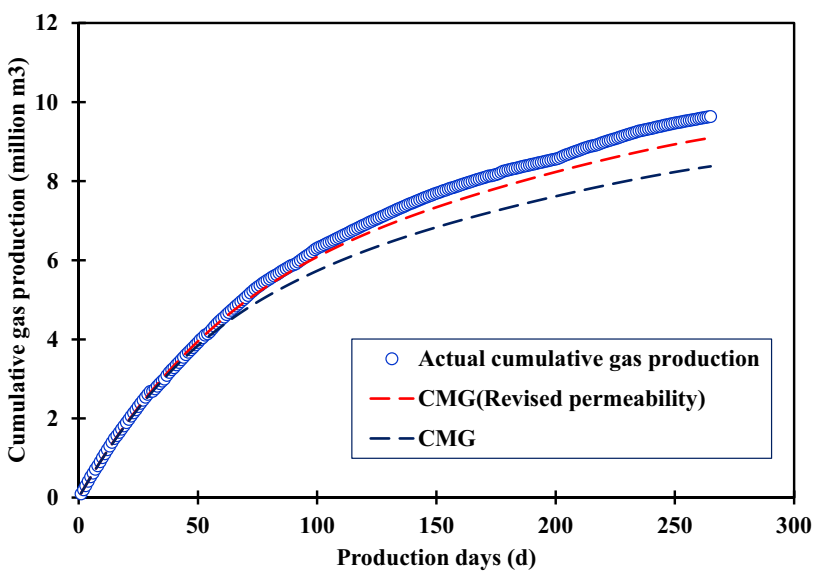

Fig. 14 The comparison of actual cumulative gas production and numerical simulation data

entire Knudsen number range. Capturing gas flow physics at nanoscale allows the proposed model free of any empirical coefficients, which is also the main distinction between our work and previous research. This research does not discuss the effect of cross-section shape of nanopores on the gastransport capacity. And the real gas effect is also neglected in this work. However, it should be noted that the proposed model in this paper can serve as a profound framework. And the real gas effect and cross-section shape can be further incorporated and investigated based on this research.

(1) In this work, advantages and disadvantages of previous models are reviewed seriously. By weight superposition of the slip flow and Knudsen diffusion, the universal non-empirical models for circular nanopore is established. Furthermore, the reliability of proposed model is demonstrated with an excellent agreement with molecular simulation results.

(2) Based on the universal gas-transport model, a novel permeability model for coal/shale matrix has been developed. And the reliability of the proposed permeability model is verified by experimental data collected from existed publications. The bulk-gas permeability model expects to lay the theoretical foundation for the next-generation numerical simulator.

(3) The contribution of slip flow will become stronger with the increasing formation pressure and the contribution of Knudsen diffusion will decrease with an increase in the formation pressure. The gas-transport capacity will increase with a decrease in the pressure. Furthermore, the greater radius the nanopores is, the stronger transport capacity will be obtained.

(4) Coupling the proposed bulk-gas permeability model with the current commercial numerical simulator, the predicted production behavior can achieve better his-

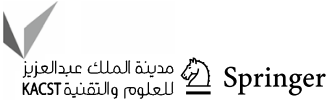


torical match. Moreover, the great difference is discovered between the revised and initial matrix permeability in the far-well region, which can be attributed to the distinction of gas-transport mechanisms.

\section{Appendix 1: The numerical simulator coupled revised permeability}

According to "Development of permeability model and analysis of influential factors" section, the matrix permeability will increase with a decrease in the pressure. Due to the pressure profile in the reservoir during the development process, there must exist differences of the matrix permeability within the whole region. Because the existed production prediction model or numerical simulator all consider the gas-transport type as the Knudsen diffusion in the shale matrix, it highlights the need to account for the actual gas-transport mechanism. Hence, in this work, the actual gas-transport capacity is obtained by the proposed permeability model (Eq. 28). Moreover, to further investigate the difference, the initial permeability is calculated by Knudsen diffusion formula (Eq. 33). The pressure profile of a shale gas well is assumed as Fig. 15:

$k_{\text {diffusion }}=\frac{\phi}{\tau} \frac{2 r}{3}\left(\frac{8 R T}{\pi M}\right)^{0.5} \frac{\mu}{P}$.

As shown in Fig. 16, the matrix permeability of the nearwell region is higher than that of the far-well region. This is because the pressure drop funnel during the production process. It also can be concluded that the initial matrix permeability is nearly equal to revised matrix permeability when the radius is less than $1 \mathrm{~m}$. However, for the far-well region, the revised matrix permeability is higher than initial

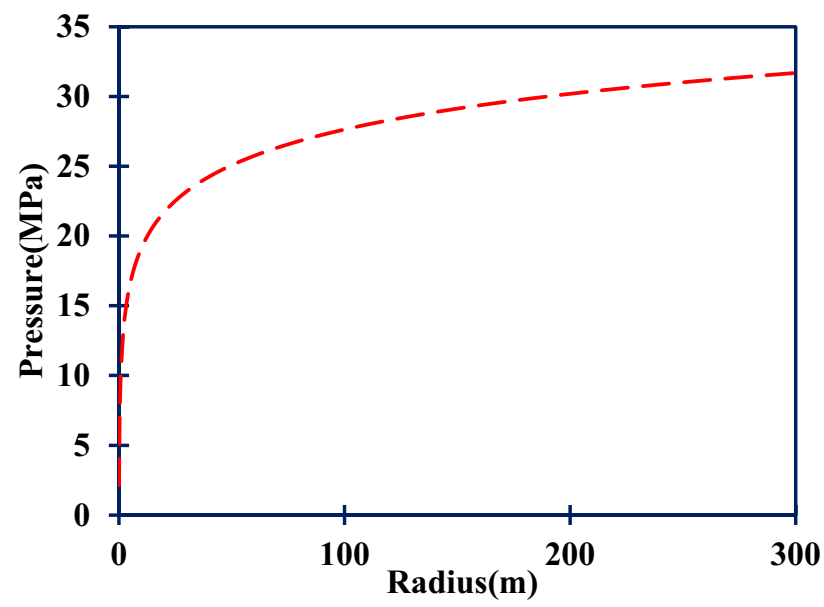

Fig. 15 The pressure profile of shale gas well

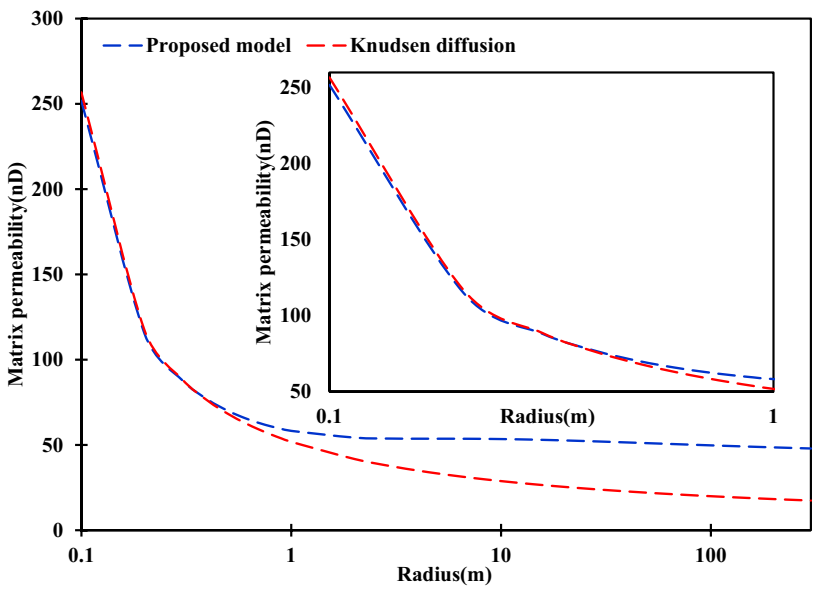

Fig. 16 The comparison between matrix permeability and revised matrix permeability

matrix permeability. In the vicinity of the production well, the Knudsen diffusion dominates the gas-transport capacity. Hence, the matrix permeability calculated by Knudsen diffusion and proposed permeability model is approximately the same. However, for the far-well region of the production well, the gas-transport mechanism converts into transition flow or slip flow. Thus, the matrix permeability of the farwell region is lower than the revised matrix permeability.

From the numerical simulator, we can obtain the pressure profile at any production time. Utilizing the pressure profile at $(n-1)$ time step, we can calculate the revised matrix permeability at $(n)$ time step. Subsequently, the revised production performance can be obtained through numerical simulator. And we can obtain the pressure profile at $(n)$ time step. Cycling these steps, we can obtain the production performance predicted by numerical simulator coupled revised permeability.

Acknowledgements The research was supported by National Natural Science Foundation of China (No. 51490654).

\section{Declarations}

Conflict of interest On behalf of all the co-authors, the corresponding author states that there is no conflict of interest.

Ethical statement On behalf of all the co-authors, the corresponding author states that there are no ethical statements contained in the manuscripts.

Open Access This article is licensed under a Creative Commons Attribution 4.0 International License, which permits use, sharing, adaptation, distribution and reproduction in any medium or format, as long as you give appropriate credit to the original author(s) and the source, provide a link to the Creative Commons licence, and indicate if changes were made. The images or other third party material in this article are included in the article's Creative Commons licence, unless indicated 
otherwise in a credit line to the material. If material is not included in the article's Creative Commons licence and your intended use is not permitted by statutory regulation or exceeds the permitted use, you will need to obtain permission directly from the copyright holder. To view a copy of this licence, visit http://creativecommons.org/licenses/by/4.0/.

\section{References}

Adzumi H (1937a) Studies on the flow of gaseous mixtures through capillaries. I The viscosity of binary gaseous mixtures. Bull Chem Soc Jpn 12(5):199-226

Adzumi H (1937b) Studies on the flow of gaseous mixtures through capillaries. II. The molecular flow of gaseous mixtures. Bull Chem Soc Jpn 12(6):285-291

Adzumi H (1937c) Studies on the flow of gaseous mixtures through capillaries. III. The flow of gaseous mixtures at medium pressures. Bull Chem Soc Jpn 12(6):292-303

Aguilera RF, Ramirez JF, Ortega CE et al (2012) A variable shape distribution (VSD) model for characterization of pore throat Radii, Drill Cuttings, Fracture Apertures and Petrophysical Properties in Tight, Shale and Conventional Reservoirs. SPE Asia Pacific Oil and Gas Conferenceand Exhibition. Society of Petroleum Engineers

Azom PN, Javadpour F (2012) Dual-continuum modeling of shale and tight gas reservoirs. In SPE annual technical conference and exhibition. Society of Petroleum Engineers

Beskok A, Karniadakis GE (1999) Report: a model for flows in channels, pipes, and ducts at micro and nano scales. Microscale Thermophys Eng 3(1):43-77

Beskok AM, Karniadakis GE, Trimmer W (1996) Rarefaction and compressibility effects in gas microflows. J Fluids Eng 118:448-456

Bi R, Nasrabadi H (2019) Molecular simulation of the constant composition expansion experiment in shale multi-scale systems. Fluid Phase Equilib 495:59-68

Bird GA (1998) Molecular gas dynamics and the direct simulation of gas flows. Clarendon Press, Oxford

Chen S, Doolen GD (1998) Lattice Boltzmann method for fluid flows. Fluid Mech 30(30):329-364

Chu S, Majumdar A (2012) Opportunities and challenges for a sustainable energy future. Nature 488(7411):294-303

Cipolla CL, Lolon EP, Erdle JC et al (2013) Reservoir modeling in shale-gas reservoirs. SPE Reserv Eval Eng 13(4):848-854

Civan F (2010) Effective correlation of apparent gas permeability in tight porous media. Transp Porous Media 82(2):375-384

Civan F, Rai CS, Sondergeld CH (2012) Determining shale permeability to gas by simultaneous analysis of various pressure tests. SPE J 17(03):717-726

Civan F, Devegowda D, Sigal RF (2013) Critical evaluation and improvement of methods for determination of matrix permeability of shale. In: SPE annual technical conference and exhibition. Society of Petroleum Engineers

Colin S (2005) Rarefaction and compressibility effects on steady and transient gas flows in microchannels. Microfluid Nanofluid 1(3):268-279

Colin S, Caen PLR (2004) Validation of a second-order slip flow model in rectangular microchannels. Heat Transf Eng 25(3):23-30

Deissler RG (1964) An analysis of second-order slip flow and temperature-jump boundary conditions for rarefied gases. Int J Heat Mass Transf 7(6):681-694

Dejam M (2018) Dispersion in non-Newtonian fluid flows in a conduit with porous walls. Chem Eng Sci 189:296-310
Dejam M (2019) Advective-diffusive-reactive solute transport due to non-Newtonian fluid flows in a fracture surrounded by a tight porous medium. Int J Heat Mass Transf 128:1307-1321

Dejam M, Hassanzadeh H, Chen Z (2017) Pre-Darcy flow in porous media. Water Resour Res 53(10):8187-8210

Deng J, Zhu W, Ma Q (2014) A new seepage model for shale gas reservoir and productivity analysis of fractured well. Fuel 124:232-240

Ebert WA, Sparrow EM (1965) Slip flow in rectangular and annular ducts. J Fluids Eng 87(4):1018-1024

Ertekin T, King GR, Schwerer FC et al (2013) Dynamic gas slippage: a unique dual-mechanism approach to the flow of gas in tight formations. SPE Form Eval 1(1):43-52

Ettehad A, Javadpour F, Sepehrnoori K (2012) Gas flow in ultra-tight shale strata. J Fluid Mech 710(12):641-658

Fu XH (2003) Coalbed methane geology. China University of Mining and Technology press, Xuzhou

Gale JFW, Reed RM, Holder J (2007) Natural fractures in the Barnett Shale and their importance for hydraulic fracture treatments. AAPG Bull 91(4):603-622

Ghanbarnezhad Moghanloo R, Javadpour F (2014) Applying method of characteristics to determine pressure distribution in 1D shale-gas samples. SPE J 19(03):361-372

Ghanizadeh A, Clarkson CR, Aquino S et al (2015) Petrophysical and geomechanical characteristics of Canadian tight oil and liquid-rich gas reservoirs: I. Pore network and permeability characterization. Fuel 153:664-681

Gray I (1987) Reservoir engineering in coal seams: part 1-the physical process of gas storage and movement in coal seams. SPE Reserv Eng 2(01):28-34

Guo C, Xu J, Wu K et al (2015) Study on gas flow through nano pores of shale gas reservoirs. Fuel 143:107-117

Harley JC, Huang Y, Bau HH et al (1995) Gas flow in micro-channels. J Fluid Mech 284:257-274

Howard JJ (1991) Porosimetry measurement of shale fabric and its relationship to illite/smectite diagenesis. Clays Clay Miner 39(4):355-361

Huang L, Zhou W, Hao Xu, Wang Lu, Zou J, Zhou Q (2021) Dynamic fluid states in organic-inorganic nanocomposite: implications for shale gas recovery and $\mathrm{CO}_{2}$ sequestration. Chem Eng $\mathrm{J}$ 411:128423

IEA (2016) World energy outlook 2016. www.eia.gov/forecast/ieo/pdf/ 0484(2016).pdf

Javadpour F (2009) Nanopores and apparent permeability of gas flow in mudrocks (shales and siltstone). J Can Pet Technol 48(08):16-21

Javadpour F, Fisher D, Unsworth M (2007) Nanoscale gas flow in shale gas sediments. J Can Pet Technol 46(10):56-61

Jia CZ (2017) Breakthrough and significance of unconventional oil and gas to classical petroleum geological theory. Pet Explor Dev 44(1):1-11

Karniadakis GE, Bekok A (2002) Microflows: fundamentals and simulation. Springer, Berlin

Karniadakis G, Beskok A, Aluru N (2005) Microflows and nanoflows: fundamentals and simulation. Cited on 123

Katsube TJ (1992) Statistical analysis of pore-size distribution data of tight shales from the Scotian Shelf. Curr Res Part E 365-372

Klinkenberg LJ (1941) The permeability of porous media to liquids and gases. Socar Proc 2(2):200-213

Knudsen M (1909) Die Gesetze der Molekularströmung und der inneren Reibungsströmung der Gase durch Röhren. Ann Phys 333(1):75-130

Kolesar JE, Ertekin T, Obut ST (1990) The unsteady-state nature of sorption and diffusion phenomena in the micropore structure of coal: Part 1-Theory and mathematical formulation. SPE Form Eval 5(01):81-88 
Liu Q, Shen P, Yang P (2002) Pore scale network modelling of gas slippage in tight porous media. Fluid Flow Transp Porous Media Math Numer Treat 295:367-375

Loyalka SK, Hamoodi SA (1990) Poiseuille flow of a rarefied gas in a cylindrical tube: solution of linearized Boltzmann equation. Phys Fluids A 2(11):2061-2065

Ma D, Duan H, Zhang Q, Zhang J, Li W, Zhou Z, Liu W (2020) A numerical gas fracturing model of coupled thermal, flowing and mechanical effects. CMC-Comput Mater Continua 65(3):2123-2141

Ma D, Zhang JX, Duan HY, Huang YL, Li M, Sun Q, Zhou N (2021) Reutilization of gangue wastes in underground backfilling mining: overburden aquifer protection. Chemosphere 264(1):128400

Mason EA, Malinauskas AP, Evans Iii RB (1967) Flow and diffusion of gases in porous media. J Chem Phys 46(8):3199-3216

Maurer J, Tabeling P, Joseph P et al (2003) Second-order slip laws in microchannels for helium and nitrogen. Phys Fluids 15(9):2613-2621

Maxwell JC (1878) On stresses in rarefied gases arising from inequalities of temperature. Proc R Soc Lond 27:304-308

Mitsuya Y (1993) Modified Reynolds equation for ultra-thin film gas lubrication using 1.5 order slip-flow model and considering surface accommodation coefficient. Trans Jpn Soc Mech Eng C 115(2):3341-3346

Nelson PH (2009) Pore-throat sizes in sandstones, tight sandstones, and shales. AAPG Bull 93(3):329-340

Pandey AK, Pratap R, Chau FS (2008) Effect of pressure on fluid damping in MEMS torsional resonators with flow ranging from continuum to molecular regime. Exp Mech 48(1):91-106

Piekos ES, Breuer KS (1996) Numerical modeling of micromechanical devices using the direct simulation Monte Carlo method. J Fluids Eng 118(3):464-469

Rahmanian M, Aguilera R, Kantzas A (2012) A new unified diffusion-viscous-flow model based on pore-level studies of tight gas formations. SPE J 18(01):38-49

Roy S, Raju R, Chuang HF et al (2003) Modeling gas flow through microchannels and nanopores. J Appl Phys 93(8):4870-4879

Sakhaee-Pour A, Bryant S (2012) Gas permeability of shale. SPE Reserv Eval Eng 15(04):401-409

Shahri MRR, Aguilera R, Kantzas A (2012) A new unified diffusionviscous flow model based on pore level studies of tight gas formations. SPE J 18(1):38-49

Sheng GL, Su YL, Wang WD (2019) A new fractal approach for describing induced-fracture porosity/permeability/compressibility in stimulated unconventional reservoirs. J Pet Sci Eng 179:855-866

Shi J, Zhang L, Li Y et al (2013) Diffusion and flow mechanisms of shale gas through matrix pores and gas production forecasting. In: SPE unconventional resources conference Canada. Society of Petroleum Engineers

Singh H, Javadpour F, Ettehadtavakkol A et al (2014) Nonempirical apparent permeability of shale. SPE Reserv Eval Eng 17(3):414-424

Siriwardane H, Haljasmaa I, Mclendon R et al (2009) Influence of carbon dioxide on coal permeability determined by pressure transient methods. Int J Coal Geol 77(1-2):109-118

Spiga GLMM (1998) Slip flow in rectangular microtubes. Nanoscale Microscale Thermophys Eng 2(4):273-282

Sreekanth AK (1969) Slip flow through long circular tubes. In: Proceedings of the 6th international symposium on rarefied gas dynamic, pp 667-680
Sun Z, Shi J, Wu K, Zhang T, Feng D, Li X (2019) Effect of pressurepropagation behavior on production performance: implication for advancing low-permeability coalbed-methane recovery. SPE J 24(02):681-697

Sun Z, Li X, Liu W, Zhang T, He M, Nasrabadi H (2020) Molecular dynamics of methane flow behavior through realistic organic nanopores under geologic shale condition: pore size and kerogen types. Chem Eng J 398:124341

Taheri P, Rana AS, Torrilhon M et al (2009) Macroscopic description of steady and unsteady rarefaction effects in boundary value problems of gas dynamics. Continuum Mech Thermodyn 21(6):423-443

Thimons ED, Kissell FN (1973) Diffusion of methane through coal. Fuel 52(4):274-280

Thompson SL, Owens WR (1975) A survey of flow at low pressures. Vacuum 25(4):151-156

Wu K, Chen ZJ (2016) Real gas transport through complex nanopores of shale gas reservoirs. In: SPE Europec featured at 78th EAGE conference and exhibition. Society of Petroleum Engineers

Wu YS, Li J, Ding D et al (2014) A generalized framework model for the simulation of gas production in unconventional gas reservoirs. SPE J 19(05):845-857

Wu K, Chen Z, Li X (2015) Real gas transport through nanopores of varying cross-section type and shape in shale gas reservoirs. Chem Eng J 281:813-825

Wu K, Chen Z, Li X et al (2016a) A model for multiple transport mechanisms through nanopores of shale gas reservoirs with real gas effect-adsorption-mechanic coupling. Int J Heat Mass Transf 93:408-426

Wu K, Li X, Guo C, Wang C, Zhangxin C (2016b) A unified model for gas transfer in nanopores of shale-gas reservoirs: coupling pore diffusion and surface diffusion. SPE J 21:1583-1611

Wu Y, Cheng L, Ma L, Huang S, Fang S, Killough JE et al (2021) Transient two-phase flow model for production prediction of tight gas wells with fracturing fluid-induced formation damage. J Pet Sci Eng 199:108351

Yan B, Alfi M, Wang Y et al (2013) A new approach for the simulation of fluid flow in unconventional reservoirs through multiple permeability modeling. In: SPE annual technical conference and exhibition. Society of Petroleum Engineers

Yang F, Ning ZF, Hu CP et al (2013) Characterization of microscopic pore structures in shale reservoirs. Acta Petrolei Sinica 34(02):301-310

Yi J, Akkutlu IY, Karacan CÖ et al (2009) Gas sorption and transport in coals: a poroelastic medium approach. Int J Coal Geol 77(1):137-144

Zhao W, Zhang T, Jia C, Li X, Wu K, He M (2020) Numerical simulation on natural gas migration and accumulation in sweet spots of tight reservoir. J Nat Gas Sci Eng 81:103454

Zou CN, Zhu RK, Bai B (2011) First discovery of nano-pore throat in oil and gas reservoir in China and its scientific value. Acta Petrologica Sinica 27(6):1857-1864

Publisher's Note Springer Nature remains neutral with regard to jurisdictional claims in published maps and institutional affiliations. 